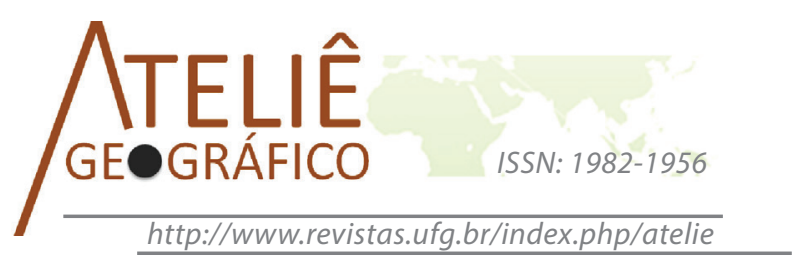

\title{
A cidade-santuário de Fátima: percepções do território religioso por meio da análise de mapas mentais
}

\author{
The city-sanctuary of Fatima: perceptions of religious \\ territory through analysis of mental maps
}

\section{La ciudad-santuario de Fátima: percepciones del territorio religioso a través de las analisis de mapas mentales}

\author{
Camila Benatti \\ Universidade Federal do Ceará \\ camilabenatti@hotmail.com
}

\begin{abstract}
Resumo
No ano de 1917, a manifestação de um fenômeno religioso em Fátima (Portugal) acabou por gerar transformações profundas em sua paisagem. A partir da crença neste acontecimento, nasce num descampado um dos maiores centros de peregrinação mundial, o Santuário de Fátima. Abordando os fenômenos religiosos sob a perspectiva geográfica, este artigo tem como principal intuito analisar e compreender as percepções dos alunos do Colégio do Sagrado Coração de Maria da cidade de Fátima em relação à cidade e ao respectivo território religioso. Como proposta de análise remeteu-se a métodos qualitativos através da elaboração de mapas mentais. A partir desta análise foi possível identificar que embora haja a carência de alguns espaços e infraestruturas direcionados às necessidades dos residentes locais, estes revelam um forte sentimento de pertença em relação ao território em estudo. Este envolvimento é refletido no reconhecimento por parte destes jovens do valor simbólico e patrimonial da cidade de Fátima enquanto lugar sagrado e religioso.
\end{abstract}

Palavras-chave: Santuário de Fátima; Lugar sagrado; Percepção do espaço; Mapas mentais.

\footnotetext{
Abstract

In the year of 1917, the manifestation of a religious phenomenon took place in Fatima, which turned out to engender profound changes in its landscape. From the belief in this event emerged in an open field the Sanctuary of Fatima, one of the largest world centers of pilgrimage. Approaching the religious phenomena from
} 
a geographical perspective, this research has the main purpose of understand and analyze the perceptions of the students of the College of the Sacred Heart of Mary of the city of Fatima in relation to the city and its religious territory. As proposed analysis referred to qualitative methods through the development of mental maps. From this analysis we found that although there is a shortage of some spaces and infrastructure targeted to the needs of local residents, they reveal a strong sense of belonging towards the area under study. This involvement is reflected in the recognition on the part of these young people the symbolic and heritage value of the city of Fatima as religious and sacred place.

Key words: Sanctuary of Fatima; Sacred place; Perception of space; Mental maps.

\begin{abstract}
Resumen
En 1917 , la manifestación de un fenómeno religioso en Fátima (Portugal ) ha generado profundos cambios en su paisaje. De la creencia en este evento, que nace en un campo uno de los mayores centros mundiales de peregrinación, el Santuario de Fátima. Dirigiéndose el fenómeno religioso desde el punto de vista geográfico, este artículo tiene el objetivo de analizar y comprender las percepciones de los estudiantes del Colegio del Sagrado Corazón de María de Fátima en relación con la ciudad y su territorio religioso. Como propuesta de análisis hace utilizado métodos cualitativos a través de la elaboración de mapas mentales. A partir de este análisis fue posible identificar que a pesar de que hay una escasez de algunos espacios e infraestructuras orientados a las necesidades de los residentes locales, estos revelan un fuerte sentido de pertenencia hacia la zona de estudio. Este compromiso se refleja en el reconocimiento por parte de estos jóvenes del valor simbólico de Fátima como un lugar religioso y sagrado.

Palabras-Claves: Santuario de Fátima; Lugar sagrado; Percepciones del espacio; Mapas mentales.
\end{abstract}

\title{
Introdução
}

O presente trabalho é fruto do desenvolvimento de uma investigação no âmbito do mestrado realizado no Instituto de Geografia e Ordenamento do Território da Universidade de Lisboa (Portugal). Como é referenciado no título - Percepções do território religioso em Fátima: uma análise por meio da aplicação de mapas mentais com os alunos do Colégio do Sagrado Coração de Maria -, a cidade de Fátima foi escolhida como o local para o desenvolvimento de pesquisa. O principal motivo desta escolha resulta da coincidência, em Fátima, de uma cidade recente que, simultaneamente, é um centro de convergência e irradiação da fé católica conhecido internacionalmente.

Perante as problemáticas de investigação que compõem a geografia da religião, este artigo se enquadra naquela que envolve o tratamento das percepções, das vivências e do sentido de lugar dos indivíduos. Neste âmbito, os estudos tradicionais desenvolvidos têm conduzido as suas atenções para a análise dos peregrinos e a prática das peregrinações. No entanto, ao concordarmos com Yi-fu Tuan (2012) na ideia de que as percepções dos autóctones são distintas das que possuem os visitantes, pareceunos particularmente relevante direcionar a preocupação central desta pesquisa para a avaliação das relações que os habitantes locais estabelecem com este espaço tão marcado pela dimensão religiosa. 
O Santuário de Fátima nasceu a partir da incidência de um fenômeno religioso que três crianças acreditaram vivenciar no ano de 1917. A difusão deste acontecimento fez com que, em poucas décadas, uma paisagem rural se transformasse em um aglomerado urbano que comporta, atualmente, um dos maiores centros de peregrinação mundial da fé católica (SANTOS, 2004). A compreensão do contexto histórico e cultural da cidade permitiu-nos delimitar o ponto condutor da presente pesquisa. Deste modo, o principal objetivo desta investigação consiste em analisar as percepções que uma pequena parcela de jovens habitantes locais possuem de Fátima enquanto cidade e território religioso. É importante considerar, analogamente, a compreensão do sentido de lugar dos residentes em relação aos lugares e aos valores culturais da cidade.

Na estruturação da dissertação de mestrado a análise e discussão dos resultados foram justapostos em duas fases. Na primeira foram descritos a tabulação dos dados dos 80 questionários aplicados na cidade de Fátima, entre os dias 23 e 27 de Abril de 2013. Os inquéritos foram orientados em três partes principais: 1) caracterização dos inquiridos; 2) conhecimento e evolução da cidade de Fátima; 3) conhecimento e relação com o território religioso. A aplicação dos inquéritos não visava abranger uma população representativa, mas, sim, possibilitar um estudo exploratório que permitisse a compreensão das percepções e sentido de lugar dos habitantes de Fátima. Neste sentido, foram analisados e discutidos os resultados que se obtiveram através dos resultados destes inquéritos.

$\mathrm{Na}$ segunda fase, foram analisados os mapas mentais aplicados aos alunos do $5^{\circ}$ ao $9^{\circ}$ ano do Colégio Sagrado Coração de Maria, localizado na Rua Jacinta Marto, na cidade de Fátima. Os mapas mentais, por sua vez, auxiliaram na concepção intrínseca das percepções dos inquiridos, que são, de acordo com Tuan (2012), influenciadas pelos valores culturais, emocionais e condições da sobrevivência biológica imbuída pelos fatores externos.

Contudo, neste artigo pretende-se demonstrar os resultados obtidos nesta segunda etapa da pesquisa: a discussão e resultados a partir da aplicação dos mapas mentais. Embora tenha sido verificada a falta de algumas infraestruturas e espaços direcionados para as necessidades da população local, foram constatados fortes laços entre os residentes e o território urbano estudado, denotando um elevado sentido de pertença e, ao mesmo tempo, um reconhecimento dos principais espaços e símbolos que assinalam a dimensão religiosa deste lugar.

\section{Fátima sob a perspectiva dos alunos do Colégio do Sagrado Coração de Maria: aplicação de mapas mentais}

A aplicação dos mapas mentais enquanto métodos de pesquisa foi implementado com o intuito de reforçar os objetivos formulados pelo presente trabalho. A realização deste método foi possível através do apoio do Colégio do Sagrado Coração de Maria da cidade de Fátima, que permitiu aos professores aplicarem os questionários (da dissertação do mestrado da autora) aos seus alunos e anexar-lhes o desenho dos mapas mentais. 
Os mapas foram aplicados por professores da escola e, devido ao fato de terem sido elaborados em horário de aula, não foi possível a participação presencial da autora da presente dissertação. Deste modo, foi ordenada a seguinte questão: "Desenhe um mapa da cidade de Fátima com o que é mais importante para si”. Participaram 16 alunos do $5 .^{\circ}$ ao $9 .^{\circ}$ ano de escolaridade, com idades compreendidas entre os 12 e os 6 anos. A elaboração dos mapas mentais teve como intuito apreender as percepções e as relações de identidade que estes alunos estabelecem com os espaços em Fátima.

Percepção, de acordo com o geógrafo Yi-Fu Tuan (2012), são as reações dos sentidos das pessoas aos reflexos do meio físico e da sociedade cultural onde vivem, em um processo no qual o que tem valor para o indivíduo fica registrado em sua memória, enquanto outros fatores são naturalmente bloqueados. Tuan (2012) afirma que à medida que o indivíduo cresce, os valores culturais conduzem com mais vigor as suas ações e vivências, de modo que as percepções são coordenadas pelas necessidades biológicas e em concordância com a cultura local. Neste sentido, Lima e Kozel (2009) acreditam que a identidade e os laços afetivos entre pessoas e lugares são fortalecidos a partir de suas vivências cotidianas, perante uma relação mútua com os objetos e grupos.

Análogo a esta ideia, está centrado o conceito de Topofilia instituído por Tuan (2012, p. 19), correspondente ao "elo afetivo entre a pessoa e o lugar ou o ambiente físico". Topofilia está intrinsecamente relacionada ao sentido de lugar e identidade das pessoas com o meio, ao envolvimento que um indivíduo mantém com um local por este lhe ser familiar e simbolizar o passado, que desperta um orgulho e sentimento de pertença no ser (TUAN, 2012).

Segundo Tuan (1975), os mapas mentais são as projeções da percepção espacial dos indivíduos, representando o conjunto de imagens e sentimentos emocionais que estes mantêm com o meio onde vivem. A corroborar esta definição, Kristina Gurjanovaite e Giedre Beconyte (2007) afirmam que o mapa mental é a percepção subjetiva do espaço geográfico real, que passa a ser transmitida cartograficamente. Estas percepções são determinadas pela educação, pela atitude psicológica, e por fatores culturais, sociais e econômicos.

De acordo com Lucas Vinícius Brunini (s/d), por meio da análise de um mapa mental é possível relacionar os locais realçados no mapa com as percepções e sentimentos que este indivíduo possui com o seu meio. Os mapas mentais permitem, assim, identificar quais os seus valores cotidianos e os lugares que lhe são mais significativos, ou seja (e retomando a terminologia definida por Tuan), apreender a topofilia inerente ao indivíduo que o elaborou. Brunini (s/d) afirma que o mapa mental possibilita examinar a observação e compreensão do indivíduo em relação ao meio em que vive. Deste modo, surge a capacidade de interpretar como se dá a sua inserção e concepção da sociedade na qual se encontra, e, ainda, os diferentes valores e significados que as pessoas conferem a cada lugar. 


\section{Os mapas mentais aplicados aos alunos do Colégio do Sagrado Coração de Maria - análise e discussão dos resultados}

Na nossa análise, os mapas mentais serão avaliados à luz de 4 critérios: 1) localização relativa dos objetos destacados no mapa; 2) locais dos objetos identificados (central ou periférico); 3) estrutura do desenho (redes viárias, arruamentos, arquitetura dos edifícios); e 4) a valorização e o significado atribuído aos lugares representados. Segundo Tuan (2012) toda cidade possui um símbolo público que representa a imagem do lugar, com o qual as pessoas se identificam. De acordo com o autor esses símbolos são reconhecidos de forma nítida.

No caso da cidade de Fátima, este símbolo é claramente identificado pelo Santuário, fato corroborado tanto nas análises dos questionários, quanto nos mapas mentais. Em todos os mapas mentais (desenhos apresentados ao fim da discussão deste artigo) o Santuário de Fátima é identificado, o que confirma este recinto como a principal expressão simbólica da cidade. De acordo com Peter Gould e Rodney White (1974), a elaboração dos mapas mentais demonstra as concepções que os indivíduos possuem do espaço, do lugar e das pessoas. A relação emocional que possuem com estes lugares é evidenciada de acordo com a posição relativa à distância de cada objeto no mapa desenhado. Gould e Rodney (1974) afirmam que o objeto que ocupa o lugar mais central no desenho, é aquele em relação ao qual o indivíduo possui maior ligação e sentimento. Isto quer dizer que à medida que os locais desenhados se forem distanciando do centro do mapa, menor será a ligação emocional do indivíduo para com ele.

Neste contexto, nos mapas de número 5, 6, 7, 10, 12 e 16 (Figuras 5, 6, 7, 10, 12 e 16) o Santuário de Fátima se encontra exatamente no centro do desenho, de modo que todos os acessos ordenados têm origem neste recinto. O santuário se estabelece, assim, como ponto fixo e central urbano, religioso e simbólico. Nos mapas 1 e 10 (Figuras 1 e 10), o santuário encontra privilégio notório: no mapa 10 (Figura 10) o único local que aparece é uma Igreja que representa o santuário; no desenho 1 (Figura 1) o mapa mental apresenta as três principais construções do santuário, que são a Basílica de Nossa Senhora de Fátima, a Capelinha das Aparições e a nova Basílica da Santíssima Trindade. Além destes três edifícios, o único lugar que é destacado no desenho é um campo desportivo. Isto demonstra que para o indivíduo que elaborou este mapa, a cidade de Fátima é, de fato, o santuário, ou seja, este é o local mais representativo da cidade.

Nos mapas 1, 2, 4, 14 e 15 (Figuras 1, 2, 4, 14 e 15), o santuário adquire destaque pela arquitetura mais elaborada na criação dos desenhos dos edifícios. Os quatro mapas são produzidos em uma estrutura circular, de modo que não aparece um edifício num ponto central. Este tipo de ordenamento cartográfico demonstra que todos os elementos realçados são os que possuem real valor para o indivíduo, em um nível hierárquico comum. Não obstante, estes mapas privilegiam a arquitetura de cada local, e deixam à margem as estruturas viárias e de arruamentos.

A respeito da textura arquitetônica há a necessidade de evidenciar os desenhos que justapõem seus moldes mais retilíneos (Figuras 4, 5, 9, 10, 11, 12 e 13). Este tipo de morfologia demonstra a valorização que os indivíduos mantêm com os lugares 
representados (Brunini, s/d). Ao contrário destes jovens, aqueles que elaboraram os mapas 1, 2, 3, 14 e 15 (Figuras 1, 2, 3, 14 e 15) detalharam mais os aspectos arquitetônicos, ratificando as suas qualidades observatórias.

A ordenação das redes viárias e de arruamentos, por sua vez, tem realce nos mapas 3, 6, 7 e 8 (Figuras 3, 6, 7 e 8). Nestes quatro mapas aparecem a Rotatória Norte. Isto acontece porque é a parte da cidade com a qual estes jovens mantém maior contato no percorrer de seus dias, sendo que o colégio onde estudam se localiza na Rua Jacinta Marto, que liga diretamente a Rotatória Norte ao Santuário. Nos mapas 6, 7 e 16 (Figuras 6, 7 e 16), no entanto, além da Rotatória Norte, é apontada também a Rotatória Sul. Esta rotatória estabelece a linha de acesso do centro (Cova da Iria) até a sede de Freguesia de Fátima, onde estão localizadas a Igreja Paroquial de Fátima e a Junta de Freguesia. A rua que concebe esta ligação é a Estrada de Fátima. Deste modo, podemos concluir que isto acontece devido às circunstâncias dos elaboradores do mapa 6, 7 e 16 (Figuras 6,7 e 16) residirem, o primeiro em Eira de Pedra (povoação pertencente à cidade de Fátima), e os dois últimos (Figuras 7 e 16) em Fátima (sede de freguesia).

Esta relação é justificada pelo fato de que por residir em Eira de Pedra e utilizar como meio deslocamento na cidade o transporte público escolar, o indivíduo do mapa 6 percorre diariamente o caminho que passa pela Rotatória Sul para chegar até o seu colégio, fazendo este percurso parte do seu cotidiano. Os elaboradores dos mapas 7 e 16 (Figuras 7 e 16), semelhantemente, ao morarem nas proximidades da sede de freguesia, fazem o trajeto que passa pela Estrada de Fátima e passa pela Rotatória Sul, até chegarem ao seu colégio. Esta observação fica marcada na sua memória pelo contato intrínseco que mantêm com o caminho realizado, seja de carro ou de bicicleta.

Outro local destacado foi a Avenida D. José Alves Correia da Silva, que aparece nos mapas 6 e 7 (Figuras 6 e 7) com o nome de "Avenida das Árvores". Depois de passarem pela Rotatória Sul é esta Avenida principal pela qual se sucede o caminho até o colégio. Além deste motivo, ao passarem a maior parte do dia no Colégio, a "Avenida das Árvores" é o local de encontro, descanso, lazer e alimentação nas horas dos intervalos das aulas e tarefas escolares.

Posições distintas foram observadas nos mapas 3, 8, 11 e 13 (Figuras 3, 8, 11 e 13), nos quais o santuário perde sua colocação central e passa a ocupar os posicionamentos periféricos dos desenhos. Nestes casos os indivíduos valorizaram outros locais nos seus mapas, lugares estes que mantêm laços mais fortes em suas práticas e vivências. Relembremos Yi-Fu Tuan (2012), que considera que as percepções dos indivíduos estão intrinsecamente relacionadas às atividades que desempenham no seu lar, nos locais de trabalho, lazer e espaços sociais coletivos. Tuan (2012) afirma que as pessoas só possuem controle de uma parcela reduzida da cidade, composta pelos seus lares, locais de vizinhança, residências de familiares próximos, e lugares de trabalho ou estudo. Nesta conjuntura, a posição de controle e vivência cotidiana exercem influências determinantes nas construções de identidade e de sentimento de pertença.

Considerando os fenômenos descritos, identificou-se nos mapas 2, 3, 4, 5, 8, 11, 14 e 15 (Figuras 2, 3, 4, 5, 8, 11, 14 e 15) o destaque atribuído ao Colégio Sagrado 
Coração de Maria, nomeado na maioria dos mapas como CSCM. Sabemos que estes jovens passam a maior parte do dia neste local a desempenharem as suas atividades escolares, tornando-o palco de desenvolvimento dos processos de controle e da construção do sentido de lugar. Atrelado aos presentes aspectos, no mapa 16 (Figura 16), podemos identificar também o local de trabalho dos pais do aluno autor desse mapa, nomeado "Meu Hotel".

Em um cenário semelhante ao envolvimento emocional e de valorização, os mapas 8, 12 e 13 (Figuras 8, 12 e 13) retratam a casa própria do elaborador. O lar representa o principal local de manifestações dos laços de identidade, pois este é o seu lugar, onde se encontram os seus objetos pessoais e sua família. É um local que representa sentimentos de segurança, controle e acolhimento. Paralelamente, nos mapas 12 e 13 (Figuras 12 e 13) são representadas as casas onde residem os seus amigos mais próximos e a casa da namorada (Figura 13), com indicações colocadas junto às próprias casas. Estes lugares são realçados pelo motivo de estarem vinculados ao local em que ocupam o seu tempo livre de lazer e descontração. O valor dos objetos representados está relacionado com os laços de amizade, diversão e liberdade de comportamentos.

Adjunto aos locais de lazer aparecem também os espaços de desporto (Figuras $1,2,11,12,13,14$ e 15), que foram representados por desenhos de campos e quadras de jogos nos mapas. Os equipamentos foram referenciados unicamente por jovens do sexo masculino, o que demonstra a relação com os jogos de quadra como futebol, futebol de salão, handebol, vôlei e basquete, corroborando a tendência de interesse que os homens têm por estas tipologias de desporto. Os locais mais mencionados foram o Campo João Paulo II (Figuras 1, 2, 12 e 15) e o Estádio Municipal de Fátima (Figuras 11, 12 e 14). Retomando aos espaços de lazer, duas jovens do sexo feminino representaram com desenhos de árvores os espaços verdes que se localizam ao redor do santuário, nos mapas 4 e 5 (Figuras 4 e 5).

Outro local identificado com presença significativa foi o supermercado Pingo Doce (Figuras 4, 11, 12, 13, 14). Há três mercados maiores na cidade: um Pingo Doce na Avenida D. José Alves Correia da Silva (Centro - "Avenida das Árvores"); outro Pingo Doce e um Minipreço na Estrada de Fátima (Fátima sede de freguesia). O Pingo Doce da Avenida D. José Alves Correia da Silva está localizado em posição paralela à rua do Colégio Sagrado Coração de Maria, avenida esta que, como vimos, foi representada nos mapas 6 e 7 (Figuras 6 e 7) com o nome de "Avenida das Árvores". A proximidade que mantêm se reflete na ligação que estes alunos possuem com a avenida. O Pingo Doce é traduzido então como local que realizam as suas necessidades relacionadas a alimentos e bebidas, sendo o local onde consomem os produtos designados para o almoço e outras refeições no decorrer do dia.

Notoriamente estes foram os principais resultados adquiridos a partir das análises dos mapas mentais, que nos permitiram perceber o grau de envolvimento emocional que dão o suporte para os sentidos de lugar e pertencimento. Deste modo, os mapas mentais se apresentaram como ponto crucial para a concepção das configurações dos lugares e seus significados para estes jovens habitantes da cidade de Fátima. 


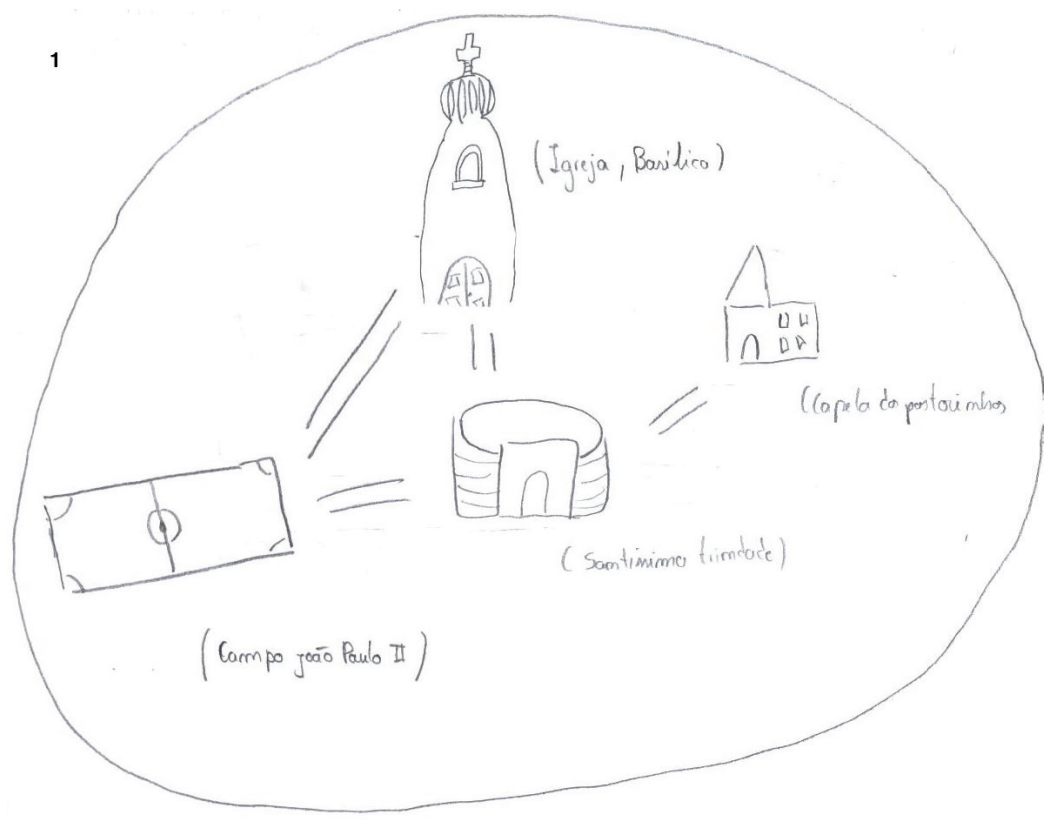

Figura 1: Mapa Mental 1.

Fonte: Elaborado pelos alunos do Colégio do Sagrado Coração de Maria, Fátima, Abril de 2013.

\section{OHapa de Fätinia}

2

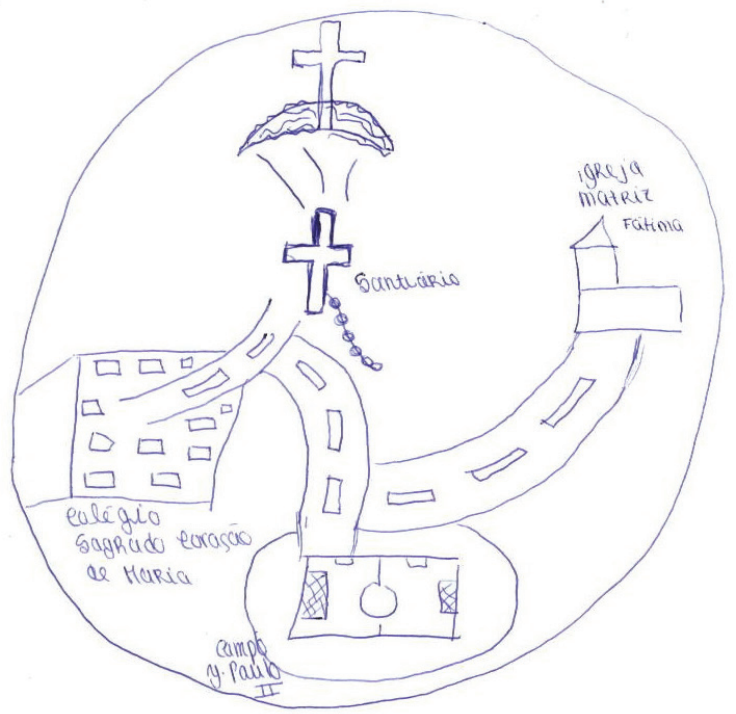

Figura 2: Mapa Mental 2.

Fonte: Elaborado pelos alunos do Colégio do Sagrado Coração de Maria, Fátima, Abril de 2013. 


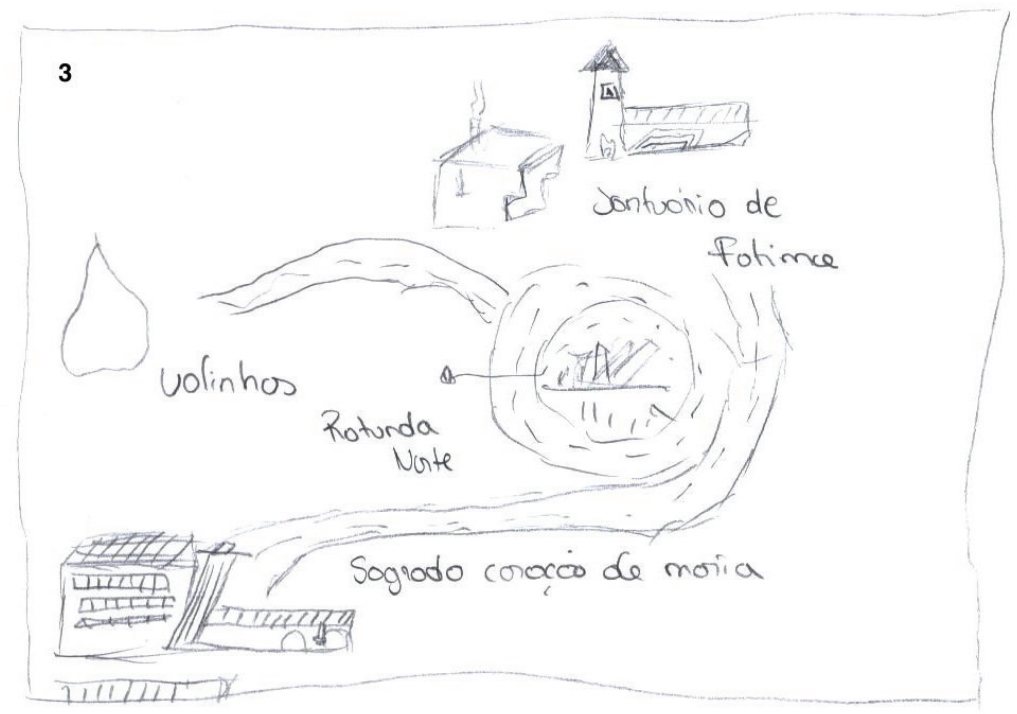

Figura 3: Mapa Mental 3.

Fonte: Elaborado pelos alunos do Colégio do Sagrado Coração de Maria, Fátima, Abril de 2013.

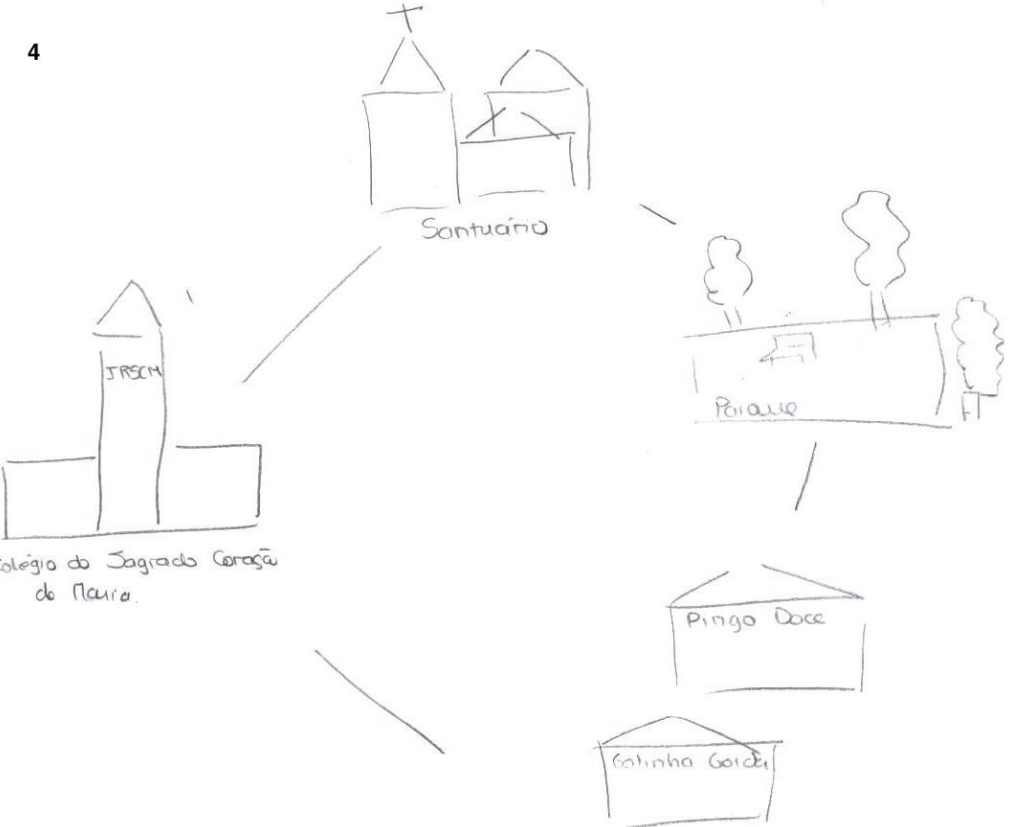

Figura 4: Mapa Mental 4.

Fonte: Elaborado pelos alunos do Colégio do Sagrado Coração de Maria, Fátima, Abril de 2013. 
5
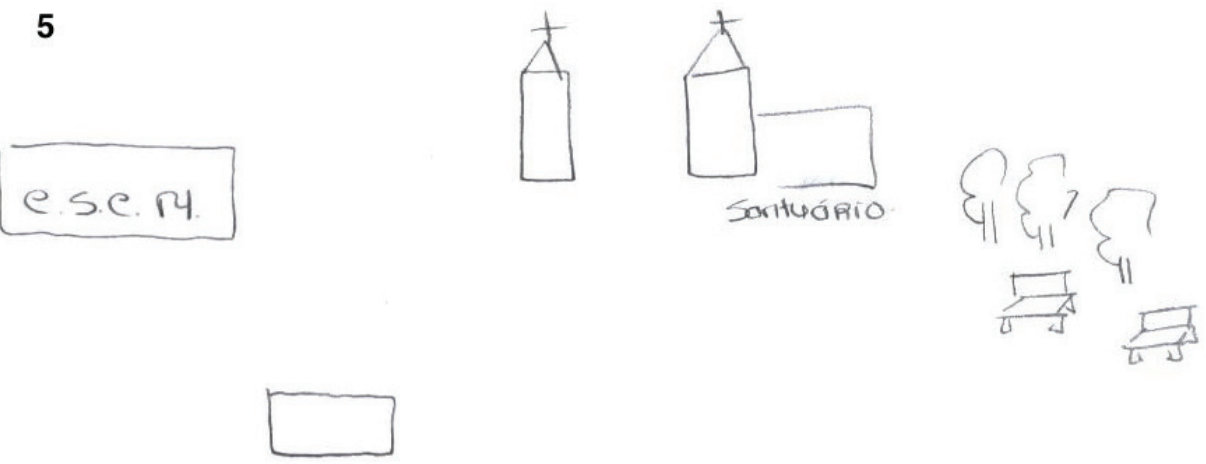

Rodoviória

Figura 5: Mapa Mental 5.

Fonte: Elaborado pelos alunos do Colégio do Sagrado Coração de Maria, Fátima, Abril de 2013.

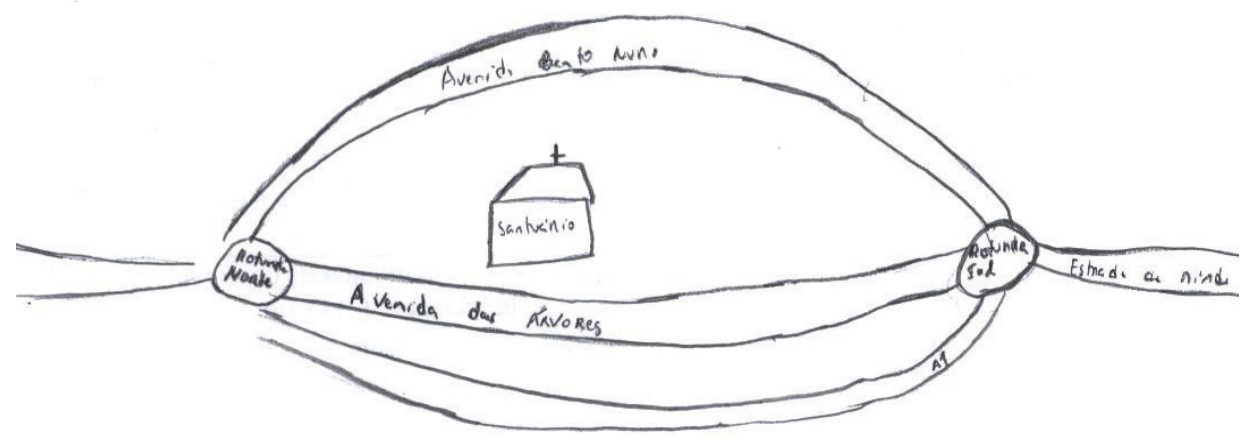

Figura 6: Mapa Mental 6.

Fonte: Elaborado pelos alunos do Colégio do Sagrado Coração de Maria, Fátima, Abril de 2013. 


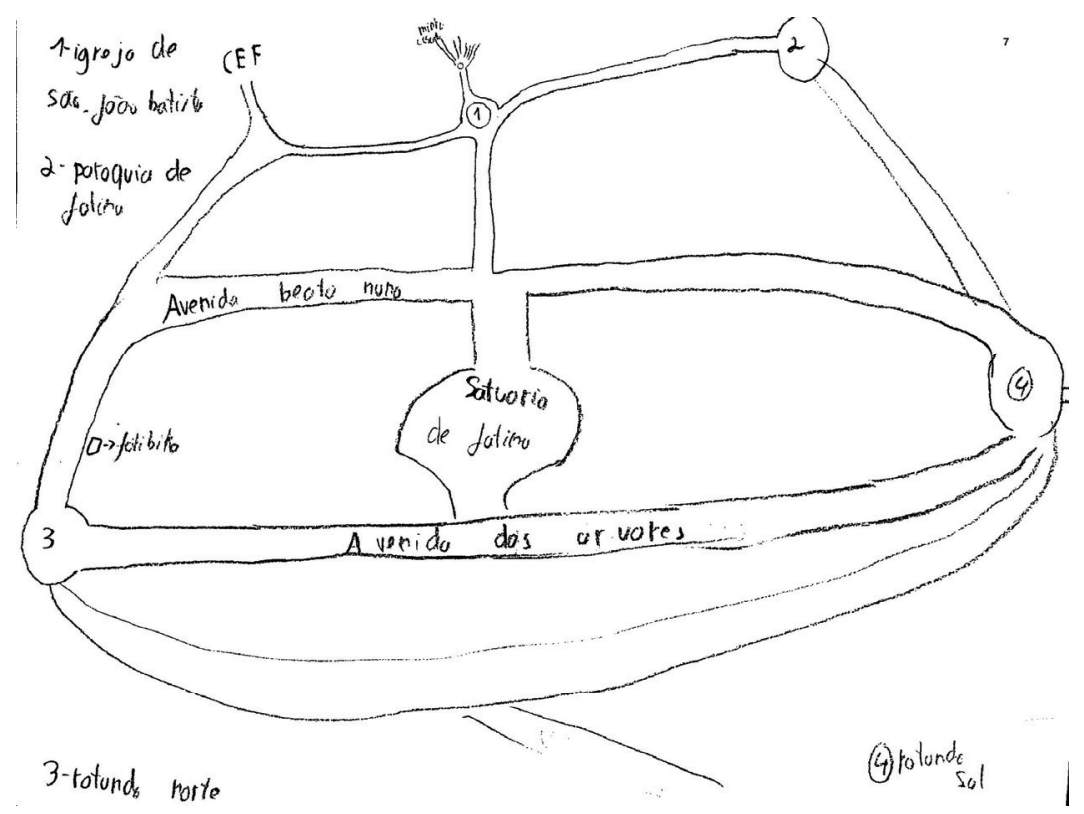

Figura 7: Mapa Mental 7.

Fonte: Elaborado pelos alunos do Colégio do Sagrado Coração de Maria, Fátima, Abril de 2013.

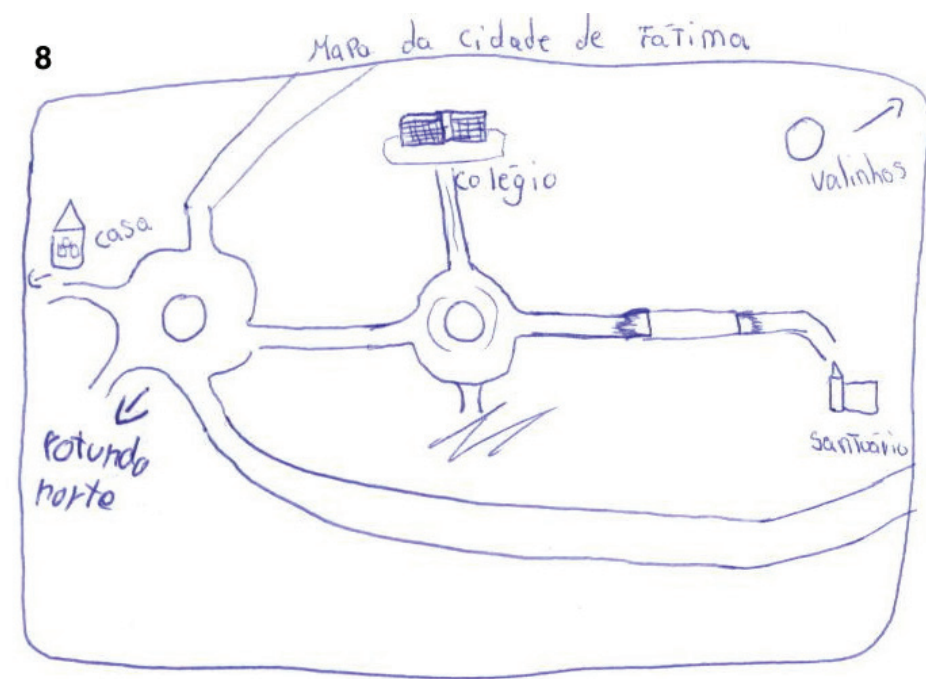

Figura 8: Mapa Mental 8.

Fonte: Elaborado pelos alunos do Colégio do Sagrado Coração de Maria, Fátima, Abril de 2013. 


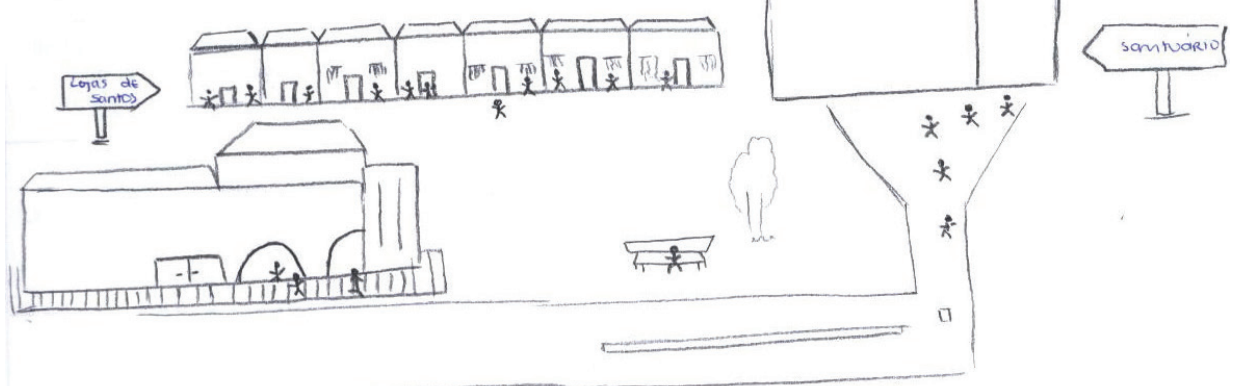

Figura 9: Mapa Mental 9.

Fonte: Elaborado pelos alunos do Colégio do Sagrado Coração de Maria, Fátima, Abril de 2013.

10

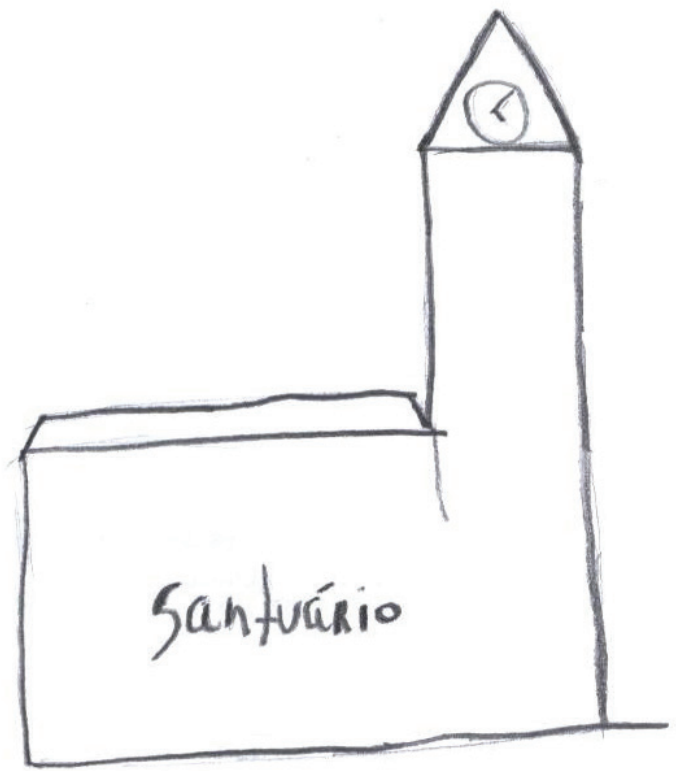

Figura 10: Mapa Mental 10.

Fonte: Elaborado pelos alunos do Colégio do Sagrado Coração de Maria, Fátima, Abril de 2013. 


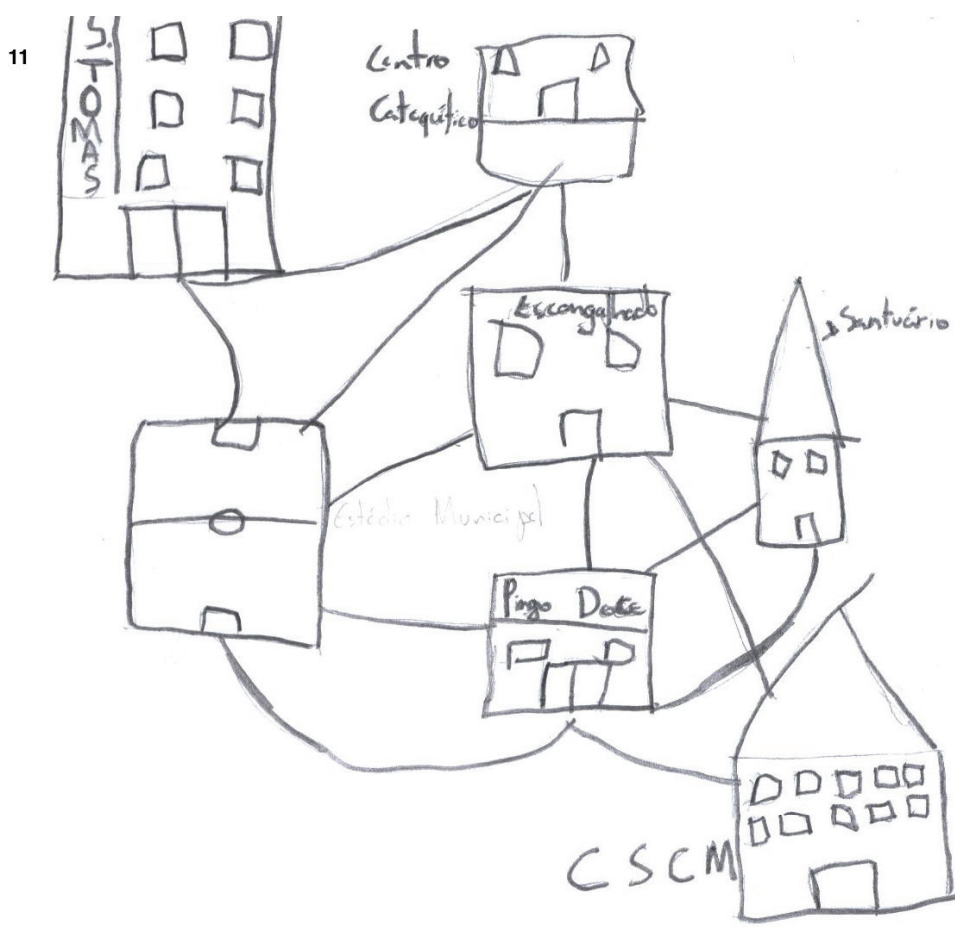

Figura 11: Mapa Mental 11.

Fonte: Elaborado pelos alunos do Colégio do Sagrado Coração de Maria, Fátima, Abril de 2013.

12<smiles>CC(C)(C)C1CCC1</smiles>

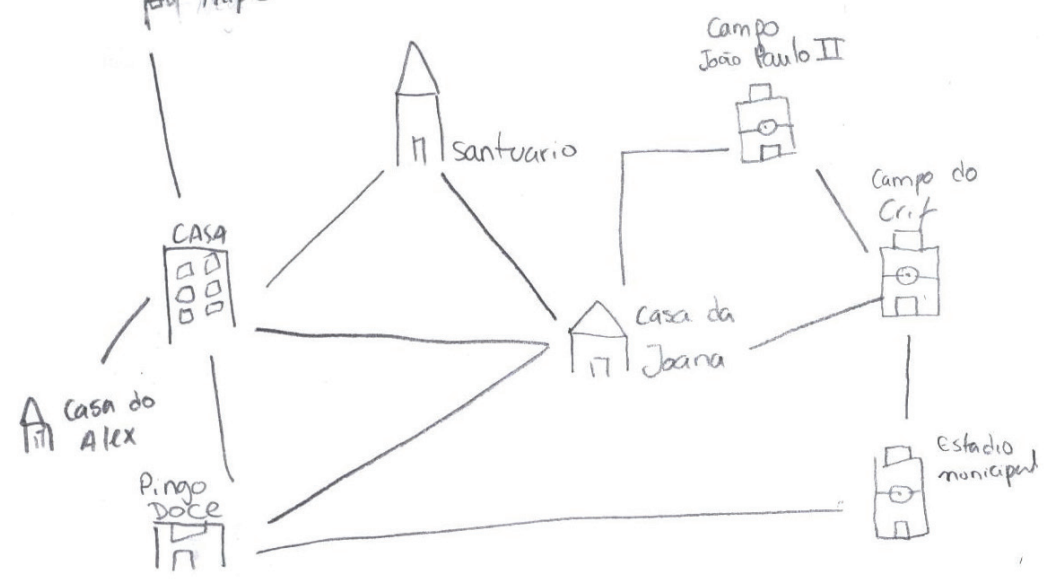

Figura 12: Mapa Mental 12.

Fonte: Elaborado pelos alunos do Colégio do Sagrado Coração de Maria, Fátima, Abril de 2013. 


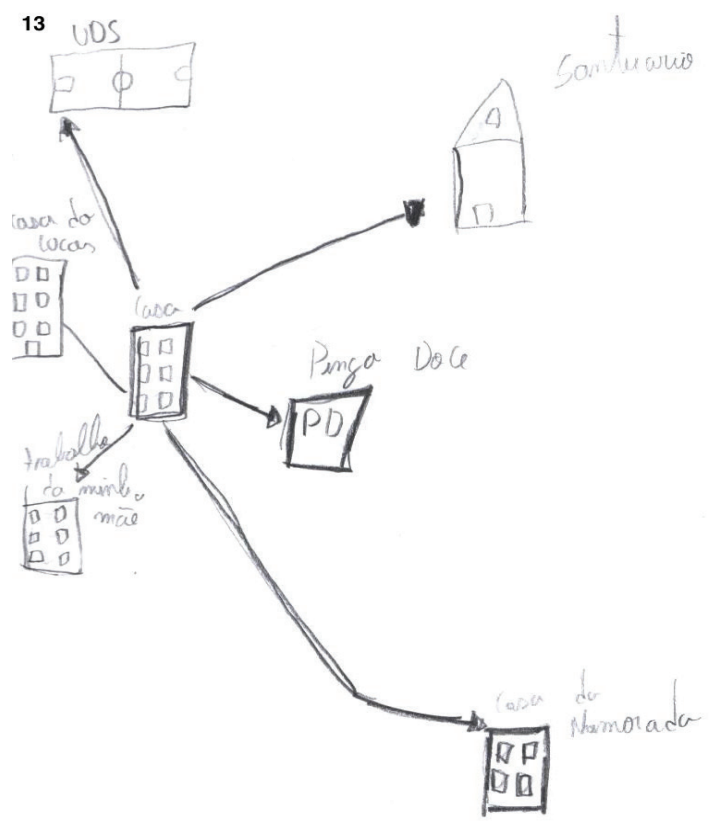

Figura 13: Mapa Mental 13.

Fonte: Elaborado pelos alunos do Colégio do Sagrado Coração de Maria, Fátima, Abril de 2013.

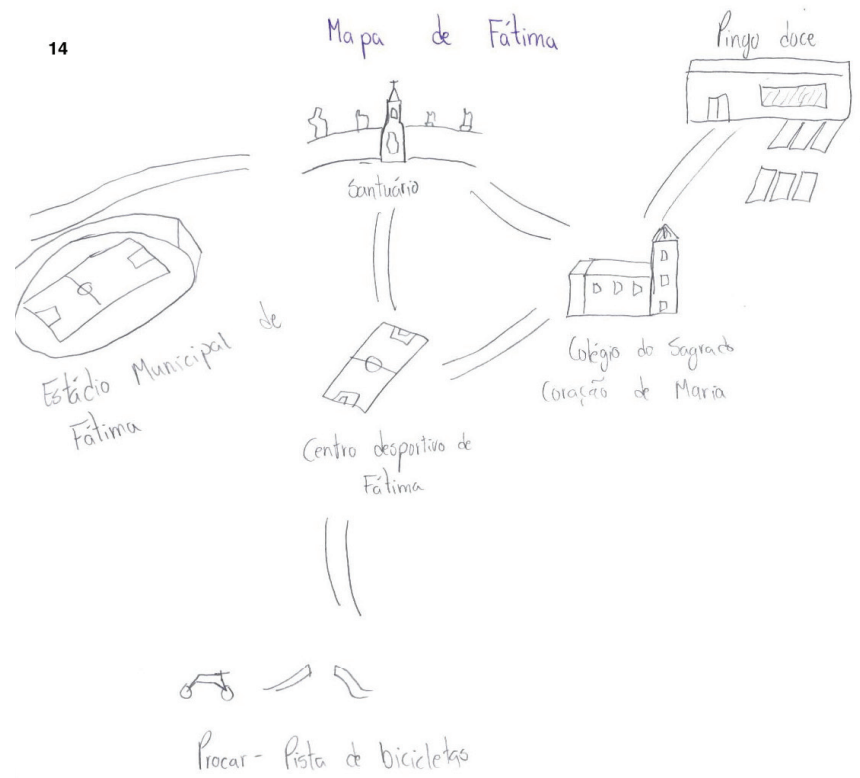

Figura 14: Mapa Mental 14.

Fonte: Elaborado pelos alunos do Colégio do Sagrado Coração de Maria, Fátima, Abril de 2013. 


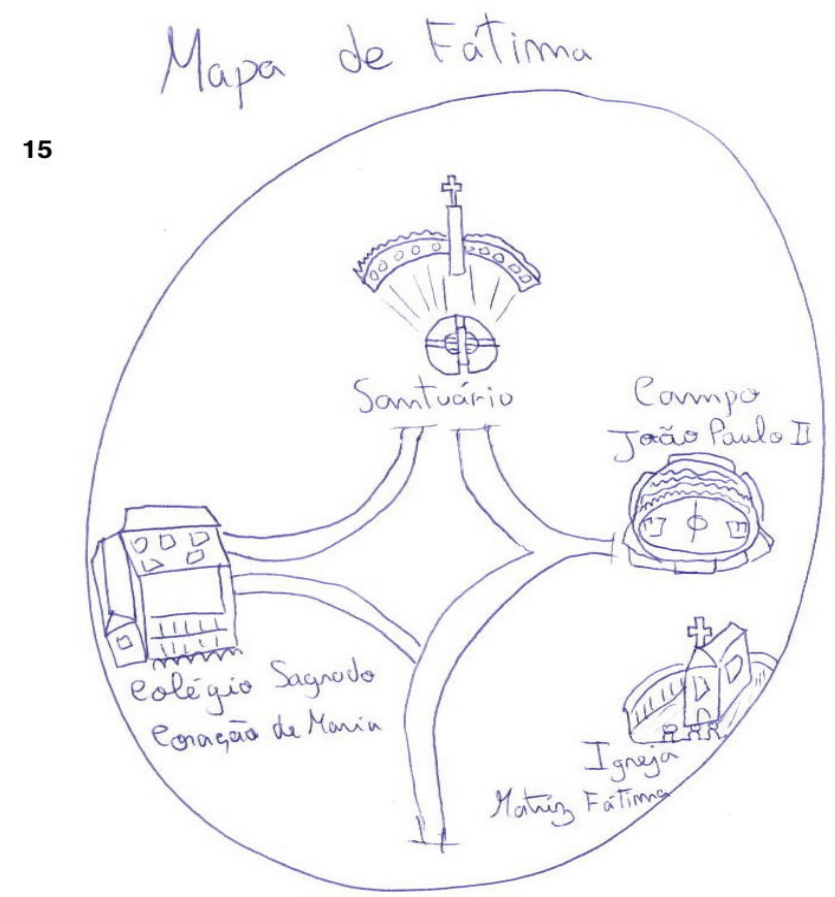

Figura 15: Mapa Mental 15.

Fonte: Elaborado pelos alunos do Colégio do Sagrado Coração de Maria, Fátima, Abril de 2013.

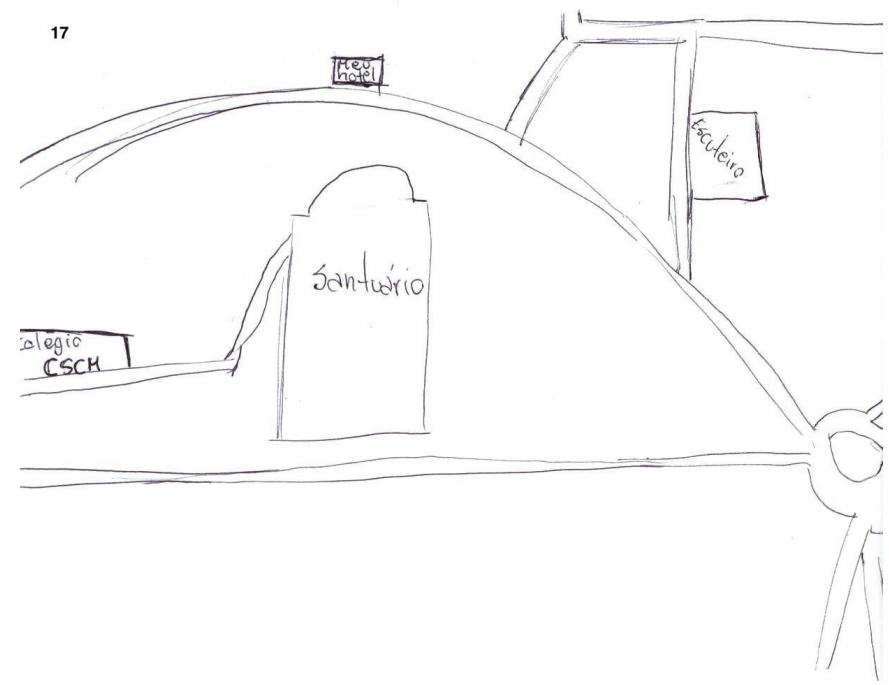

Figura 16: Mapa Mental 16.

Fonte: Elaborado pelos alunos do Colégio do Sagrado Coração de Maria, Fátima, Abril de 2013. 


\section{Considerações finais}

As discussões estruturadas ao longo deste artigo, designados à temática central de investigação, nos conduziram a conclusões que retomam o fio condutor deste estudo. A situação específica da cidade e do Santuário de Fátima direcionam os levantamentos para possíveis continuidades de estudo e contribuições científicas para a geografia da religião e, ainda, para o campo geográfico como um todo. Os resultados adquiridos se tornam conhecimentos parciais da amálgama do pensamento teórico e empírico do fenômeno religioso sob a luz geográfica.

O objetivo principal foi identificar quais as percepções e o sentido de lugar de pequena parcela de jovens habitantes locais da cidade de Fátima em relação à cidade e ao seu território religioso. Deste modo, o estudo de campo foi realizado através da elaboração de 16 mapas mentais pelos alunos do $5^{\circ}$ ao $9^{\circ}$ ano do Colégio do Sagrado Coração de Maria.

Os instrumentos conduzidos referentes à aplicação dos mapas mentais nos forneceram algumas conclusões relevantes. Ao compreender os valores culturais que influenciam as práticas e experiências dos indivíduos, estas se mostram evidentes nas disposições cartográficas territoriais apresentadas nos mapas. O Santuário de Fátima se impõe como lugar representativo da cidade, se confirmando como a principal expressão simbólica de Fátima para os seus habitantes.

A partir da certificação que os mapas mentais permitem relativamente à identificação das percepções e do sentido de lugar dos indivíduos em relação aos espaços da cidade, são destacados os locais que demonstram estes envolvimentos. O conjunto de imagens que se apresentam confirmam os sentimentos emocionais, de pertença e controle valorizados pelos elaboradores dos mapas. Deste modo, são relevados a casa própria do indivíduo, e o local de estudo - Colégio do Sagrado Coração de Maria - e o local de trabalho dos pais, que denotam segurança e controle. Os espaços de lazer, descanso e encontros aparecem representados por casas de amigos, pelos espaços verdes em torno do santuário, e pela "Avenida das Árvores", nome designado pelos jovens para a Avenida D. José Alves Correia da Silva, local de descanso e lazer nos intervalos das aulas.

À sua maneira, podemos concluir que as percepções e o sentido de lugar destes jovens são calcados por fatores históricos intrínsecos à memória coletiva local. Os fatores culturais, sociais e econômicos contribuem efetivamente para as construções simbólicas e identitárias que, por sua vez, mantêm as relações afetivas destes residentes com o território. Deste modo, as percepções dos elaboradores dos mapas se refletem nas atitudes e no sentido de lugar que se relacionam, reciprocamente, com os lugares da cidade. Para além dos laços de identidade existentes entre os alunos do Colégio do Sagrado Coração de Maria e o território, esses jovens reconhecem o valor simbólico que Fátima possui nas várias dimensões do cotidiano da população local e da cidade, e, sobretudo, na influência expressa no universo religioso e católico. 


\section{Referências}

BRUNINI, Lucas V. O mapa mental: percepção do espaço e identidade no processo ensino-aprendizagem da geografia. Votuporanga: Centro Universitário de Votuporanga, sem data.

GOULD, Peter; WHITE, Rodney. Mental Maps. Penguin: Hamondsworth, 1974.

GURJANOVAITE, Kristina; BECONYTE, Giedre. Cartographic analysis of general geographic elements in children mental maps. ICC2007 Conference Proceedings (Electronic), Moscow, 2007. Disponível em: <http://icaci.org/files/documents/ICC proceedings/ICC2007/html/Proceedings.htm>. Acesso em: 28 de Maio de 2013.

LIMA, Angélica M. L.; KOZEL, Salete. Lugar e mapa mental: uma análise possível. Geografia, Londrina, vol. 18, n. 1, p. 207-231, jan./jun., 2009.

SANTOS, Maria da Graça. P. Espiritualidade e território: estudo geográfico de Fátima. Coimbra: Universidade de Coimbra, 2004.

TUAN, Yi-Fu. Images and Mental Maps. Annals of Association of American Geographers, vol. 65, p. 205-213, 1975.

Topofilia. Tradução de Lívia de Oliveira. Londrina: Editora Universidade Estadual de Londrina (Eduel), 2012.

Camila Benatti

Doutoranda em Geografia pela Universidade Federal do Ceará. Bacharel em

Turismo pela Universidade Federal de Ouro Preto e Mestre em População,

Sociedade e Território pelo Instituto de Geografia e Ordenamento do Território da Universidade de Lisboa.

UFC, Departamento de Geografia, Laboratório de Estudos Geoeducacionais

(LEGE). Campus do Pici - Bloco 902. Cep: 60455-760 - Fortaleza, CE - Brasil

E-mail: camilabenatti@hotmail.com 